\title{
BRIEF COMMUNICATION OPEN On the importance of time-resolved electrochemical evaluation in corrosion inhibitor-screening studies
}

\author{
Peyman Taheri ${ }^{\circledR}$, Ingrid Milošev $\mathbb{D}^{2}$, Mats Meeusen ${ }^{1}$, Barbara Kapun ${ }^{2}$, Paul White $\mathbb{D}^{3}$, Anton Kokalj $\mathbb{D}^{2}$ and Arjan Mol $\mathbb{D}^{1}$
}

Efficiency of corrosion inhibitors in aqueous solutions depends on several interfacial parameters, which may vary over time. Therefore, reliable electrochemical techniques are demanded for screening the efficiency of corrosion inhibitors and monitoring their performance over time. Here, we evaluate corrosion inhibition efficiency of imidazole-based compounds on bare Cu surfaces and highlight the importance of electrochemical evaluation of the inhibitor over time, characterized by linear polarization resistance techniques as a reliable, instantaneous and non-invasive method for assessing intrinsic inhibitor performance in lab screening studies.

npj Materials Degradation (2020)4:12; https://doi.org/10.1038/s41529-020-0116-z

\section{INTRODUCTION}

The restrictions of using hexavalent chromium-based corrosion protection chemistries, due to their potential harmful environmental and health impacts, have provoked the need of introducing alternative chemical compounds, including those for corrosion inhibitors. Rare-earth-, vanadate-, lithium-, phosphate-, metal- and organic-based compounds have been developed to date to replace the existing hexavalent chromium-based inhibitors $^{1}$. A large number of commercial corrosion inhibitors are available, whereas new products are being introduced to meet specific industrial needs ${ }^{2-4}$.

A selection of new alternative corrosion inhibitors is a rather difficult task due to the diversity and complexity of corrosion phenomena and due to variation of their performance with time. The selection of an inhibitor is usually based on results of laboratory or field tests. Corrosion inhibition mechanisms depend on several parameters that are, one way or another, associated with the properties of basic constituents of the corrosion system, that is, the inhibitor, metal (oxide) surface and electrolyte ${ }^{5,6}$. Some of these parameters may vary during corrosion leading to a change of the inhibitor performance ${ }^{7-9}$. The selection becomes more unreliable when several corrosion inhibitors are screened and evaluated at only one specific exposure time. Therefore, realtime monitoring of the inhibition efficiency versus the exposure time is demanded for reliable interpretations, while fast data acquisition is required to shorten the inhibitor-screening process. To date, there are several high-throughput screening methods based on mass loss ${ }^{10,11}$, microscopic and analytical testing ${ }^{12,13}$, electrochemical measurements ${ }^{14-16}$, and computational modeling $^{17-19}$ to assess the corrosion inhibition of a large number of compounds.

Here, we aim to screen the performance of corrosion inhibitors over prolonged exposure times of $100 \mathrm{~h}$. We examine corrosion inhibition of $1 \mathrm{mM}$ imidazole $(\mathrm{ImiH}), 1$-methyl-benzimidazole (BimMe) and 2-mercapto-1-methyl-benzimidazole (SH-BimMe) in 3 wt.\% $\mathrm{NaCl}$ aqueous solutions on pure $\mathrm{Cu}$ samples over an exposure period of $100 \mathrm{~h}$ and compare the results with an uninhibited solution. We compare potentiodynamic polarization (PDP), electrochemical impedance spectroscopy (EIS), and linear polarization resistance (LPR) techniques for screening of the inhibitors over time. Note that evaluation of the inhibition mechanism demands a wider set of characterization techniques, but is not deemed to be of highest priority during initial inhibitorscreening studies.

\section{RESULTS AND DISCUSSION}

Polarization methods involve sweeping the sample potential and recording the current passing through the cell. PDP is often used for laboratory testing, because it provides useful information about the corrosion inhibition mechanisms and corrosion rate of the substrate in inhibited environments. Figure $1 \mathrm{a}-\mathrm{c}$ shows the polarization curves of the inhibited and uninhibited $\mathrm{Cu}$ samples, recorded after 1,30 and $100 \mathrm{~h}$ of immersion, at $1 \mathrm{mV} \mathrm{s}^{-1}$ scan rate, starting $250 \mathrm{mV}$ negative to open circuit potential $\left(E_{\mathrm{oc}}\right)$, and then increasing the potential in the anodic direction. Changes of the anodic and cathodic branches of the uninhibited sample by the exposure time indicate an ongoing corrosion process, i.e., oxygen reduction as the major cathodic reaction and formation of cuprous chloride complexes as the dominant anodic reaction ${ }^{20}$. It can be seen that the addition of inhibitors shifts $E_{\text {corr }}$ to more positive values, except for $\mathrm{ImiH}$ and BimMe at $100 \mathrm{~h}$ for which the PDP curve is very similar to that of uninhibited sample. The comparison of PDP curves clearly shows that SH-BimMe is a much better inhibitor than ImiH and BimMe and that its inhibition efficiency increases with time: notice the remarkable decrease of current density at $100 \mathrm{~h}$. In contrast, the performances of ImiH and BimMe decrease with time and further analysis shows that they even slightly accelerate corrosion at longer exposure times (vide infra).

Figure 1d-f presents EIS impedance modulus Bode plots of the inhibited and uninhibited $\mathrm{Cu}$ samples at different exposure times, recorded at a $10 \mathrm{kHz}-10 \mathrm{mHz}$ frequency range with 10 frequency points per logarithmic decade with an amplitude of $10 \mathrm{mV}$. Impedance modulus values at a frequency of $0.01 \mathrm{~Hz}(|Z|)$ are taken as a parameter reflecting corrosion resistance of the inhibitor/substrate interface ${ }^{21}$. The values deduced from the EIS plots at different exposure times are tabulated in Table 1. The reduced $|Z|$ values indicate that $I \mathrm{miH}$ is an accelerator after $30 \mathrm{~h}$ of immersion, while SH-BimMe acts as an inhibitor with strongly

${ }^{1}$ Department of Materials Science and Engineering, Delft University of Technology, Mekelweg 2, 2628 CD Delft, The Netherlands. ${ }^{2}$ Department of Physical and Organic Chemistry, Jožef Stefan Institute, Ljubljana, Slovenia. ${ }^{3}$ CSIRO Manufacturing, Clayton, VIC 3168, Australia. ${ }^{凶}$ email: p.taheri@tudelft.nl 

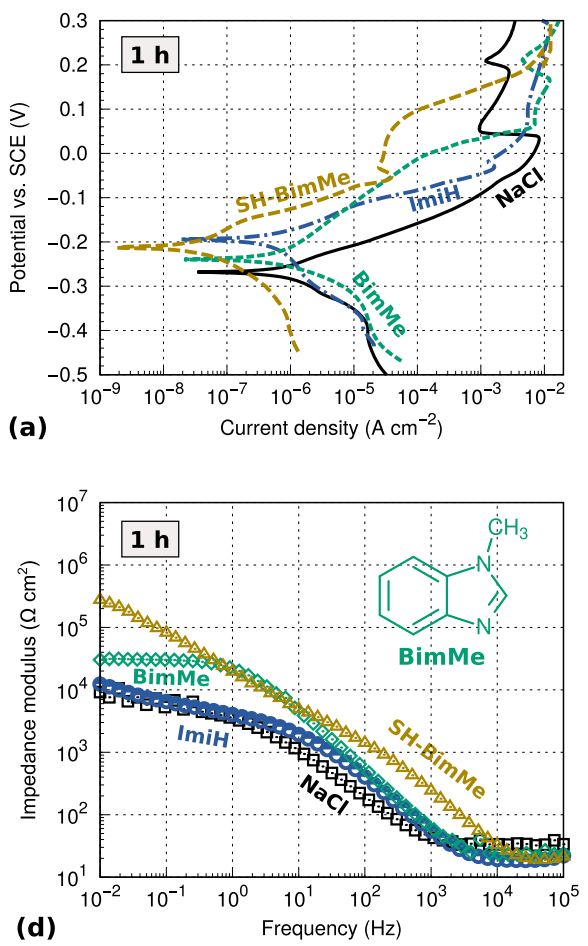
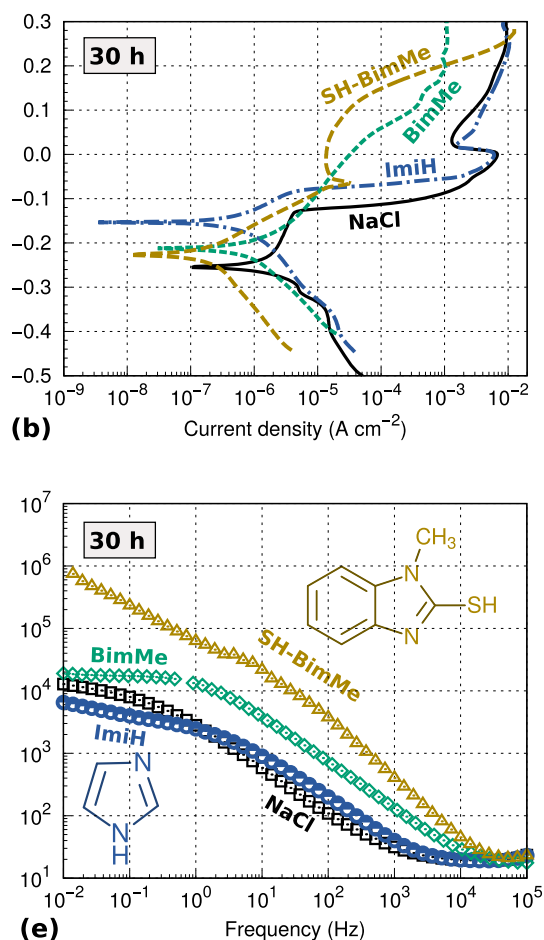
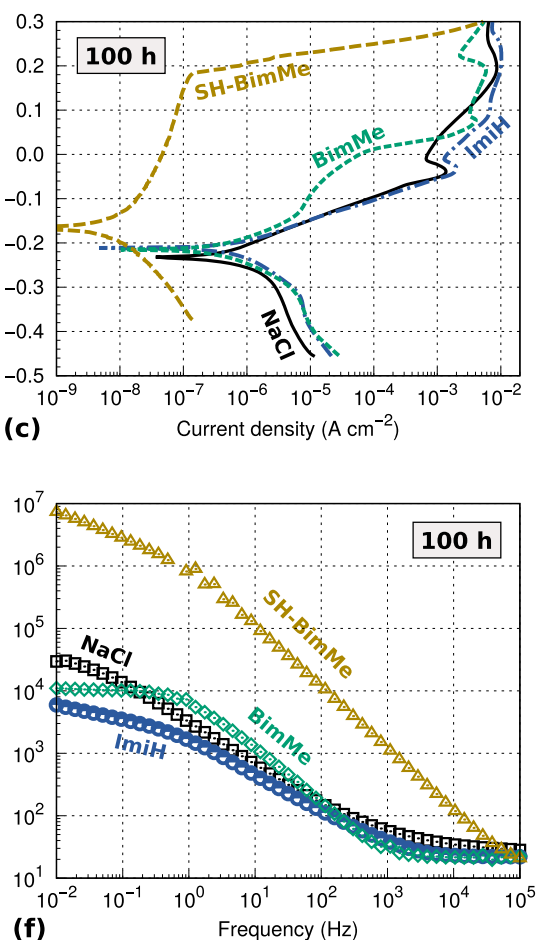

Fig. 1 PDP curves and EIS Bode plots of Cu samples in 3 wt.\% NaCl without and with $1 \mathrm{mM}$ ImiH, BimMe, and SH-BimMe. a-c PDP curves and $\mathbf{d}$-f EIS Bode plots, recorded at 1, 30 and $100 \mathrm{~h}$ immersion time. Skeleton formulae of the three inhibitors are shown in d and e; for SHBimMe the thiol tautomer is shown, although the thione tautomer is more stable in the solution; our DFT calculations further reveal that in the adsorbed state $\mathrm{SH}$-BimMe exists either as thiolate or thione, but not as thiol ${ }^{29}$.

Table 1. Impedance modulus values $|Z|$ at $0.01 \mathrm{~Hz}$ for uninhibited $(\mathrm{NaCl})$ and inhibited (ImiH, BimMe and $\mathrm{SH}-\mathrm{BimMe})$ samples recorded after 1,30 and $100 \mathrm{~h}$ of immersion.

\begin{tabular}{lccl}
\hline Sample & \multicolumn{3}{l}{ Impedance modulus at $0.01 \mathrm{~Hz}\left(\mathrm{k} \Omega \mathrm{cm}^{2}\right)$} \\
\cline { 2 - 4 } & $1 \mathrm{~h}$ & $30 \mathrm{~h}$ & $100 \mathrm{~h}$ \\
\hline $\mathrm{NaCl}$ & 9.3 & 12.8 & 29.7 \\
ImiH & 12.4 & 6.5 & 5.9 \\
BimMe & 30.4 & 19.0 & 11.0 \\
SH-BimMe & 276.2 & 746.5 & 7326 \\
\hline
\end{tabular}

increasing efficiency with time, as evidenced by the tabulated $|Z|$ values. According to the tabulated $|Z|$ values, BimMe acts as an inhibitor at early exposure times, but its efficiency decreases with time so that it accelerates corrosion after $100 \mathrm{~h}$.

Despite some discrepancy between PDP and EIS results, both techniques deliver complementary information about the corrosion inhibition mechanism. However, they are unsuitable for the preceding screening step as they suffer from various issues to provide time-resolved corrosion inhibitor performance information over the exposure time. For the PDP, polarization of the surfaces at the anodic and cathodic potentials varies the surface physicochemical properties by its electrochemical activation, possibly changing the surface composition and substrateinterface chemistry from the original unbiased condition ${ }^{22-25}$. In addition, a new sample should be used for each measurement as the polarization interrupts the corrosion/inhibition processes. On the other hand, the excitation signal applied for EIS is small $(10 \mathrm{mV})$ to assure linearity, but sweeping the frequency range of $10 \mathrm{kHz}-10 \mathrm{mHz}$ takes about $15 \mathrm{~min}$ for conventional corrosion/ inhibition systems. Therefore, the surface is altered by the electrolyte during the measurement time implying that the generated EIS plot lacks stationarity ${ }^{14,25-28}$. Note that a relatively wide frequency range must be scanned to generate interpretable EIS graphs, regardless of subsequent data point(s) selection for interpretations. On the other hand, the excitation signal, i.e., sweeping a potential window frequently, during the EIS measurement makes the system more complex over LPR that uses only one potential sweep. In terms of data interpretation, EIS typically require additional surface analysis measurements to relate the electrochemical data to the physicochemical surface state of the sample under study and this consideration makes EIS less suitable for screening large numbers of corrosion inhibitors.

LPR method, used widely in electrochemistry, involves only slight polarization of the sample, typically in the order of $\pm 10 \mathrm{mV}$, relative to its $E_{\mathrm{oc}}$. As the DC potential is changed slightly, a current will be induced flowing between the working and counter electrodes. Therefore, the material's resistance to polarization can be extracted from the slope of the linear region of the potential versus current density curve as schematically shown in Fig. 2a. This polarization resistance $\left(R_{\mathrm{p}}\right)$ is essentially inversely proportional to the corrosion current density $\left(i_{\text {corr }}\right)$ where the greater $R_{\mathrm{p}}$ values refer to a better corrosion inhibition as indicated by the following formula:

$i_{\text {corr }}=\beta\left[\frac{\Delta i}{\Delta E}\right]_{\Delta E \rightarrow 0}$

where $E$ is the potential $(\mathrm{V}), i_{\text {corr }}$ is the corrosion current density (A $\left.\mathrm{cm}^{-2}\right)$, and $\beta$ is the constant associated with anodic $\left(b_{\mathrm{a}}\right)$ and cathodic $\left(b_{\mathrm{c}}\right)$ Tafel slopes, i.e., $\beta=b_{\mathrm{a}} b_{\mathrm{c}} /\left[2.3\left(b_{\mathrm{a}}+b_{\mathrm{c}}\right)\right]$.

Figure $2 \mathrm{~b}$ shows LPR values obtained from the $I-E$ curves collected in $\pm 10 \mathrm{mV}$ potential range versus $E_{\mathrm{oc}}$. The $R_{\mathrm{p}}$ values of $\mathrm{SH}$-BimMe are substantially higher than those of uninhibited and ImiH and BimMe inhibited samples, indicating a superior corrosion inhibition of SH-BimMe. In addition, $R_{\mathrm{p}}$ values of $\mathrm{SH}$-BimMe increase initially followed by a subsequent leveling indicating a gradual reaction of the inhibitors with the surface followed by a 

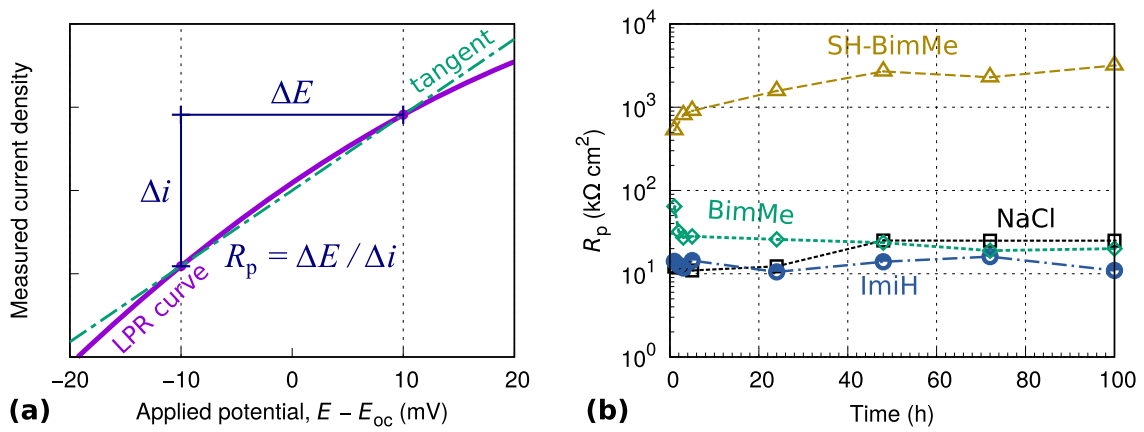

Fig. 2 LPR principle and results of LPR measurements. a Schematic of the extraction of the LPR value from the $I-E$ curve and $\mathbf{b} R_{\mathrm{p}}$ values of uninhibited $(\mathrm{NaCl})$ and inhibited $(\mathrm{ImiH}, \mathrm{BimMe}$ and $\mathrm{SH}-\mathrm{BimMe}) \mathrm{Cu}$ samples as functions of exposure time.

saturation or simultaneous construction and degradation of the interfaces. In contrast, $R_{\mathrm{p}}$ values of ImiH for exposure times above $20 \mathrm{~h}$ fall below those of uninhibited sample, indicating that ImiH even slightly accelerates corrosion, whereas $R_{\mathrm{p}}$ of BimMe starts from relatively high value followed by a sharp drop at early hours of the exposure. These observations indicate that the inhibition efficiencies of corrosion inhibitors may vary significantly over the exposure period.

Although the ranking of inhibitors is rather obvious from Fig. 2b, such a visual inspection becomes cumbersome when a large number of inhibitors is screened. To this end, it is convenient to extract from data a single number that represents the efficiency of a given inhibitor. This can be achieved by first estimating the mean value of $R_{\mathrm{p}}$, for example, via trapezoidal numerical integration over time:

$\left\langle R_{\mathrm{p}}\right\rangle=\frac{1}{t_{N}-t_{0}} \int_{t_{0}}^{t_{N}} R_{\mathrm{p}}(t) \mathrm{d} t \approx \frac{1}{t_{N}-t_{0}} \sum_{k=1}^{N} \frac{R_{\mathrm{p}}\left(t_{k-1}\right)+R_{\mathrm{p}}\left(t_{k}\right)}{2} \Delta t_{k}$,

where $\Delta t_{k}=t_{k}-t_{k-1}$, where $t_{\mathrm{k}}$ are discrete times at which $R_{\mathrm{p}}$ was measured (note that in the case of a uniform sampling of points, the integral of Eq. (2) can be approximated by a simple arithmetic mean). The inhibition efficiency $(\eta)$ is then calculated via the wellknown relation, $\eta=\left(R_{\mathrm{p}}^{\mathrm{inh}}-R_{\mathrm{p}}^{\text {blank }}\right) / R_{\mathrm{p}}^{\mathrm{inh}}$, where superscripts "inh" and "blank" stand for inhibited and uninhibited samples, respectively. In the current case, we obtain about $-50 \%$ for $\mathrm{ImiH}$, $12 \%$ for BimMe and $99 \%$ for $\mathrm{SH}-\mathrm{BimMe}$; note that the negative value for ImiH indicates that it accelerates corrosion. There are other ways of how inhibition efficiency can be calculated, e.g., instead of $\left\langle R_{\mathrm{p}}>\right.$ one can calculate $\left\langle 1 / R_{\mathrm{p}}\right\rangle$ or one can calculate $\eta$ value at each measured point and then take the mean of $\eta$; these various ways are analyzed in the Supplementary information. Our analysis reveals that all the three ways give very similar results for good inhibitors (the discrepancy appears only for very time-fluctuating data or when $\eta$ is low or negative).

The LPR measurements for screening of inhibitors benefit from real-time evaluation over the exposure time without applying a wide range of potential thus avoiding variation of the interfacial properties expected for PDP measurements. This eliminates the change of sample's conditions while generating each data point, which in turn enables efficient recording of many data points. Moreover, collecting each data point lasts a few seconds, and therefore, substantial variation of the sample as for the conventional EIS measurement is eliminated. These issues make LPR a powerful technique for lab screening of a large number of inhibitors on bare samples exposed to ionically conductive electrolytes with controlled compositions over a long exposure time.

To summarize, inhibition efficiency of corrosion inhibitors may vary over the exposure time. Corrosion inhibitors exhibiting excellent performances at early exposure stages may perform differently after longer exposure times, or vice versa. Hence, for the many corrosion inhibitor-screening studies that are executed these days it is shown not to be sufficient to report corrosion inhibitor performance data at one single moment in time: timeresolved information during relatively long exposure times is crucial for obtaining insights in the intrinsic robustness of corrosion inhibitors studied. To this end, LPR is a useful method, because it is a fast, non-invasive and relatively simple electrochemical testing technique for lab screening of multiple corrosion inhibitors on bare samples exposed to ionically conductive electrolytes with controlled compositions over the exposure time delivering real-time electrochemical assessments. In contrast, PDP changes the surface properties due to the application of a relatively large potential range, which makes it unsuitable for screening of inhibitors versus time. On the other hand, conventional EIS takes several minutes to sweep the frequency range for a single measurement, while corrosion/inhibition processes are ongoing, which may affect stationarity of the experiment. In addition, EIS data interpretation is a challenge, typically requiring in-depth surface analytical information to correlate a relevant physicochemical surface state to the observed frequency-resolved electrochemical responses. Therefore, time-resolved LPR is recommended for the initial evaluation of corrosion inhibitors in the lab that is focused only on the intrinsic inhibitor performance, i.e., for the screening process for which quick and easily interpretable data are required.

\section{METHODS}

\section{Samples}

Copper samples (99.95\% purity) were supplied by Goodfellow Cambridge Ltd. Samples were cut from 2-mm-thick foil and ground using, successively, 1200, 2400 and 4000-grid SiC emery papers successively (LaboPol-5, Struers, Ballerup, Denmark), cleaned ultrasonically in ethanol for $5 \mathrm{~min}$, rinsed with deionized water and dried in a stream of $\mathrm{N}_{2}$.

Samples were immersed in $3 \mathrm{wt} . \% \mathrm{NaCl}$ aqueous solution with or without the addition of imidazole (ImiH), 1-methyl-benzimidazole (BimMe) and 2-mercapto-1-methyl-benzimidazole (SH-BimMe) at $1 \mathrm{mM}$ concentration. All inhibitors were supplied by Sigma Aldrich (purity for ImiH 99.5\%, SH-BimH 98\% and SH-BimMe 95\%), and $\mathrm{NaCl}$ by Carlo Erba (pro analysis).

\section{Instrumentation}

Electrochemical measurements were performed in a three-electrode corrosion cell at the room temperature. The $\mathrm{Cu}$ substrate formed the working electrode with exposed surface of $1.0 \mathrm{~cm}^{2}$. A platinum mesh was used as the counter electrode and a saturated calomel electrode (SCE) as the reference electrode. All potentials in this work refer to the SCE scale.

Measurements were carried out with potentiostat Autolab PGSTAT 12 (Metrohm Autolab, Nova software 2.1.3, Utrecht, The Netherlands). Linear polarization curves were collected in the potential range of $\pm 10 \mathrm{mV}$ versus $E_{\mathrm{oc}}$. Values of polarization resistance $\left(R_{\mathrm{p}}\right)$ were determined from slopes of the current density versus potential. Potentiodynamic curves then were recorded at $1 \mathrm{mV} \mathrm{s}^{-1}$ potential scan rate. Electrochemical impedance 
spectroscopy (EIS) measurements were performed in the $10 \mathrm{kHz}-10 \mathrm{mHz}$ frequency range with 10 frequency points per logarithmic decade and sinusoidal voltage of $10 \mathrm{mV}$.

\section{DATA AVAILABILITY}

The authors declare that all data supporting the findings of this study are available within the paper and its Supplementary Information files.

Received: 20 January 2020; Accepted: 12 March 2020; Published online: 24 April 2020

\section{REFERENCES}

1. Gharbi, O., Thomas, S., Smith, C. \& Birbilis, N. Chromate replacement: what does the future hold? npj Mater. Degrad. 2, 12 (2018).

2. Liu, Z. F., Bai, X., Zhang, L. H. \& Zhang, Y. L. Synthesis and properties of environmentally friendly scale and corrosion inhibitor. Appl. Mech. Mater. 618, 180-183 (2014).

3. Lgaz, H. et al. Synthesis and evaluation of some new hydrazones as corrosion inhibitors for mild steel in acidic media. Res. Chem. Intermed. 45, 2269 (2019).

4. Migahed, M. A., Abdul-Raheim, A. M., Atta, A. M. \& Brostow, W. Synthesis and evaluation of a new water soluble corrosion inhibitor from recycled poly(ethylene terphethalate). Mater. Chem. Phys. 121, 208-214 (2010).

5. Sulaiman, K. O., Onawole, A. T., Faye, O. \& Shuaib, D. T. Understanding the corrosion inhibition of mild steel by selected green compounds using chemical quantum based assessments and molecular dynamics simulations. J. Mol. Liq. 279, 342-350 (2019).

6. Granese, S. L., Rosales, B. M., Oviedo, C. \& Zerbino, J. O. The inhibition action of heterocyclic nitrogen organic compounds on $\mathrm{Fe}$ and steel in $\mathrm{HCl}$ media. Corros. Sci. 33, 1439-1453 (1992).

7. Podobaev, N. I. \& Avdeev, Y. G. Temperature and time effects on the acid corrosion of steel in the presence of acetylenic inhibitors. Prot. Met. 37, 529 (2001).

8. Villamizar-Suarez, W., Malo, J. M., Martinez-Villafañe, A. \& Cha-con-Nava, J. G. Evaluation of corrosion inhibitors performance using real-time monitoring methods. J. Appl. Electrochem. 41, 1269-1277 (2011).

9. Sullivan, J. et al. In situ monitoring of corrosion mechanisms and phosphate inhibitor surface deposition during corrosion of zinc-magnesium-aluminium (ZMA) alloys using novel time-lapse microscopy. Faraday Discuss. 180, 361-379 (2015).

10. Winkler, D. A. et al. Using high throughput experimental data and in silico models to discover alternatives to toxic chromate corrosion inhibitors. Corros. Sci. 106, 229-235 (2016).

11. White, P. A. et al. A new high-throughput method for corrosion testing. Corros. Sci. 58, 327-331 (2012).

12. White, P. A. et al. High-throughput channel arrays for inhibitor testing: proof of concept for AA2024-T3. Corros. Sci. 51, 2279-2290 (2009).

13. Muster, T. H. et al. A rapid screening multi-electrode method for the evaluation of corrosion inhibitors. Electrochim. Acta 54, 3402-3411 (2009).

14. Meeusen, M. et al. A complementary electrochemical approach for time-resolved evaluation of corrosion inhibitor performance. J. Electrochem. Soc. 166, C3220-C3232 (2019)

15. Garcia, S. J. et al. Validation of a fast scanning technique for corrosion inhibitor selection: influence of cross-contamination. Surf. Interface Anal. 42, 205-210 (2010).

16. Garcia, S. J. et al. The influence of $\mathrm{pH}$ on corrosion inhibitor selection for AA2024T3 assessed by high-throughput technique (multielectrode) and potentiodynamic testing. Electrochim. Acta 55, 2457-2465 (2010).

17. Winkler, D. A. et al. Towards chromate-free corrosion inhibitors: structureproperty models for organic alternatives. Green. Chem. 16, 3349-3357 (2014).

18. Mondal, S. K. \& Taylor, S. R. The identification and characterization of organic corrosion inhibitors: correlation of a computational model with experimental results. J. Electrochem. Soc. 161, C476-C485 (2014).

19. Feiler, C. et al. In silico screening of modulators of magnesium dissolution. Corros. Sci. 163, 108245 (2020).

20. Milošev, I., Kovačević, N., Kovač, J. \& Kokalj, A. The roles of mercapto, benzene and methyl groups in the corrosion inhibition of imidazoles on copper: I. Experimental characterization. Corros. Sci. 98, 107-118 (2015).

21. MacDonald, J. R. \& Johnson, W. Impedance Spectroscopy, Theory, Experiment and Application (John Wiley \& Sons, Hoboken, 2005).

22. Neufeld, P. Application of the polarization resistance technique to corrosion monitoring. Corros. Sci. 4, 245-251 (1964).
23. Mansfeld, F. Tafel slopes and corrosion rates from polarization resistance measurements. Corrosion 29, 397-402 (1973).

24. Kelly, R. G., Scully, J. R., Shoesmith, D., \& Buchheit, R. G. Electrochemical Techniques in Corrosion Science and Engineering 1st edn (CRC Press, Boca Raton, 2002).

25. Meeusen, M. et al. The use of odd random phase electrochemical impedance spectroscopy to study lithium-based corrosion inhibition by active protective coatings. Electrochim. Acta 278, 363-373 (2018).

26. Assiongbon, K. A., Emery, S. B., Pettit, C. M., Babu, S. V. \& Roy, D. Chemical roles of peroxide-based alkaline slurries in chemical. Mechanical polishing of Ta: investigation of surface reactions using time-resolved impedance spectroscopy. Mater. Chem. Phys. 86, 347 (2004).

27. Harvey, T. G. et al. The effect of inhibitor structure on the corrosion of AA2024 and AA7075. Corros. Sci. 53, 2184-2190 (2011).

28. Garcia et al. Unravelling the corrosion inhibition mechanisms of bi-functional inhibitors by EIS and SEM-EDS. Corros. Sci. 69, 346-358 (2013).

29. Kovačević, N., Milošev, I. \& Kokalj, A. The roles of mercapto, benzene, and methyl groups in the corrosion inhibition of imidazoles on copper: II. Inhibitor-copper bonding. Corros. Sci. 98, 457-470 (2015).

\section{ACKNOWLEDGEMENTS}

This work is a part of M.Era-Net project entitled "Coin Desc: Corrosion inhibiton and dealloying descriptors". The financial support of the project by NWO (Nederlandse Organisatie voor Wetenschappelijk Onderzoek) and MESS (Ministry of Education, Science and Sport of Republic of Slovenia) is acknowledged. A.K. acknowledges helpful discussion with Prof. Daniel Crespo from UPC Barcelona.

\section{AUTHOR CONTRIBUTIONS}

P.T. and I.M. conducted the measurements and data analysis and wrote the main text of the manuscript. B.K. and M.M. contributed in the measurements and data analysis. A.K. conducted data analysis, plotted figures and wrote Supplementary information. P.W. contributed in developing the experimental approach and data analysis. J.M.C.M. contributed in developing the overall research strategy, conducted data analysis and supervised the work. All coauthors read and edited the manuscript.

\section{COMPETING INTERESTS}

The authors declare no competing interests.

\section{ADDITIONAL INFORMATION}

Supplementary information is available for this paper at https://doi.org/10.1038/ s41529-020-0116-z.

Correspondence and requests for materials should be addressed to P.T.

Reprints and permission information is available at http://www.nature.com/ reprints

Publisher's note Springer Nature remains neutral with regard to jurisdictional claims in published maps and institutional affiliations.

Open Access This article is licensed under a Creative Commons Attribution 4.0 International License, which permits use, sharing, adaptation, distribution and reproduction in any medium or format, as long as you give appropriate credit to the original author(s) and the source, provide a link to the Creative Commons license, and indicate if changes were made. The images or other third party material in this article are included in the article's Creative Commons license, unless indicated otherwise in a credit line to the material. If material is not included in the article's Creative Commons license and your intended use is not permitted by statutory regulation or exceeds the permitted use, you will need to obtain permission directly from the copyright holder. To view a copy of this license, visit http://creativecommons. org/licenses/by/4.0/.

(c) The Author(s) 2020 